\title{
WAVE-INDUCED OVERWASH AND DESTRUCTION OF SAND DUNES
}

\author{
Jens Figlus $^{1}$, Nobuhisa Kobayashi ${ }^{1}$, Christine Gralher $^{1}$ and Vicente Iranzo $^{1}$
}

\begin{abstract}
Numerical modeling of the rapid dune profile changes that may occur due to wave overtopping and sediment overwash during a storm is challenging. One of the reasons is the limited amount of available field and laboratory data related to the problem. Another reason is the complex interaction of hydrodynamics, morphological changes and sediment transport in the intermittently wet and dry zone of the dune profile. We modified the cross-shore numerical model CSHORE on the basis of three laboratory overwash tests with different dune geometries in front of a lowcrested vertical wall to include the capability to predict profile evolution due to wave overtopping and overwash. Experimental results show that the transition from minor to major overwash is fairly rapid and that the resilience of the dune against destruction by wave-induced overwash is dependent on its geometry. Computed results compare well with the measured hydrodynamics, profile changes, wave overtopping rates and sediment overwash rates, requiring only one empirical parameter to be calibrated. Only the erosion in front of the vertical wall in the last phase of each test is not predicted well by the model. Additional comparisons with field data on profile evolution involving overwash verifies the field capabilities of CSHORE.
\end{abstract}

Keywords: overwash; dune erosion; sediment transport; numerical modeling

\section{INTRODUCTION}

Coastal sand dunes are the last line of defense against flooding due to storm surge and wave attack for millions of people living in close proximity to coastlines all over the world. During severe storm events, waves may overtop the dune crest causing landward transport of sediment and water. The landward transport of water over the highest profile elevation is called wave overtopping and similarly, the landward transport of sediment is termed overwash. The erosion of the dune and the rapid lowering of the dune crest lead to an increase in wave overtopping and overwash which may culminate in the destruction of the entire dune if the storm conditions persist. Despite this imminent threat to lives and property, knowledge of overwash processes and modeling capabilities are still limited (Donnelly et al., 2006). This is mostly due to the complex nature of sediment transport mechanisms and the limited amount of comprehensive laboratory and field data sets related to this problem.

In the present lab experiment, overwash transport rates and high resolution profile changes were measured for three different initial dune profiles in front of a low-crested vertical wall in a movablebed wave flume. This setup corresponds to dunes in front of a seawall or dunes with relatively steep landward slopes located on a low backshore. An innovative sand trap located inside a water collection basin behind the vertical wall enabled us to measure the temporal variations of overwash transport rates and sediment characteristics. Each of the three tests was continued even after the exposure of the wall in order to examine the effect of wave overtopping on beach erosion in front of the wall.

The present study aims at creating a unique set of laboratory data pertaining to longshore uniform wave-induced overwash of dunes. Measured profile and overwash evolution is separated into three phases of minor overwash, major overwash and beach erosion in front of the wall. These data are then used to modify and calibrate the numerical model CSHORE (Kobayashi et al. 2009), developed to predict berm and dune erosion in the absence of wave overtopping. In the following, the experiment setup, instrumentation, collected data, and analysis procedures are explained briefly. A more detailed description of the experiment is given by Figlus et al. (2010).

The emphasis of this paper is on the numerical model CSHORE, especially the modifications related to overwash. Comparisons between the measured data and CSHORE are presented to show the capability and difficulty in capturing the essential hydrodynamic and morphological processes during the transition from minor to major overwash. Additionally, the modified CSHORE is compared with field measurements of pre and post storm dune profiles of severe erosion with and without overwash. The comparisons indicate that the latest CSHORE can predict dune erosion and overwash under various conditions if one empirical parameter in CSHORE is calibrated. Finally, the experimental and numerical results are summarized and conclusions are presented.

\footnotetext{
${ }^{1}$ Center for Applied Coastal Research, Department of Civil \& Environmental Engineering, University of Delaware, 259 Academy St, Newark, DE, 19716, USA, E-mail: jens@udel.edu
} 


\section{EXPERIMENT}

Three different initial beach profiles including a berm and dune (BD), a wide dune (WD), and a sloping beach with dune (SD) were constructed in a flume section of the University of Delaware's Sand Tank before being exposed to identical storm tide and wave conditions. The beach profiles were constructed on top of a 1:30 plywood slope with the same volume of well sorted fine sand $\left(d_{50}=\right.$ $0.18 \mathrm{~mm}$ ). The sands specific gravity $s$, its porosity $n$, and its average fall velocity $w_{f}$ were $2.6,0.4$, and $2.0 \mathrm{~cm} / \mathrm{s}$, respectively. Specific gravity $s$ is the ratio of sand density $\rho_{s}$ to fresh water density $\rho$. The flume section was $23 \mathrm{~m}$ long and $1.15 \mathrm{~m}$ wide with a low-crested vertical wall at the landward end.

Fig. 1 shows a schematic of the flume cross-section including the experiment instrumentation (left panel) and the geometry of the three initial dune profiles for the BD, WD, and SD tests (right panel). Multiple series of 400-s irregular wave trains following a TMA spectral shape with $H_{m o}=0.19 m$ and $T_{p}$ $=2.6 \mathrm{~s}$ were created by a piston-type wave maker located offshore in $1 \mathrm{~m}$ water depth. Each test was continued until the dune was destroyed and the entire profile was submerged below SWL. The resilience of the three dune shapes against destruction by wave induced overwash depended on the initial geometry as shown later.
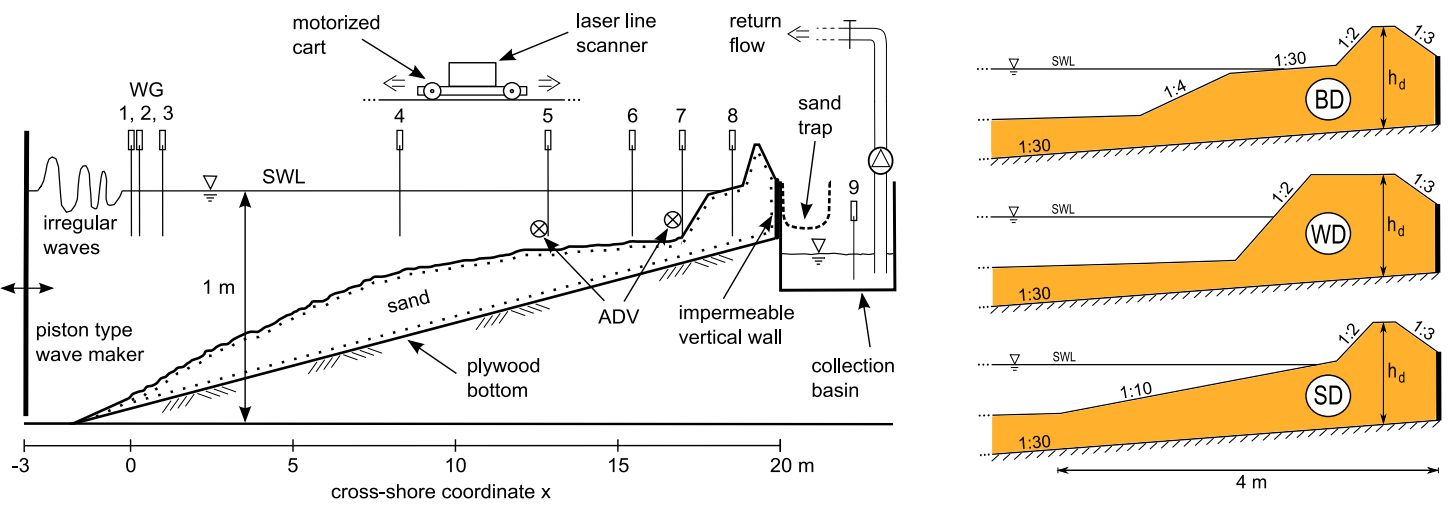

Figure 1. Schematic of wave flume setup (left panel) and initial dune geometries for the BD, WD, and SD tests (right panel).

Hydrodynamic measurements included flow velocity via two acoustic Doppler velocimeters (ADV) and free surface elevation using 8 capacitance wave gauges (WG). The wires of the most shoreward gauges were buried in the bed to avoid exposure to air and to allow for collection of data in the intermittently wet and dry zone of the profile. Offshore wave conditions and run repeatability were checked by WG1 through WG3, where three gauges are necessary to separate incident and reflected wave signals following Kobayashi et al. (1990). Data from WG4 through WG8 showed the transformation of the shoaling wave train as it travels from offshore (wave paddle) toward onshore (dune). WG4 and WG5 captured a majority of the changes related to wave breaking, whereas WG6, WG7, and WG8 gave insight into inner surf zone dynamics and wave uprush on the beach-dune system. WG9 was used in combination with a mechanical float gauge to measure the water level in the collection basin.

The cross-shore positions of ADV1 and ADV2 were right next to WG5 and WG7, respectively, with ADV measuring volumes placed at an elevation of $2 / 3$ of the local water depth below still water level (SWL). ADV1 was a downward looking probe measuring all three flow components, whereas ADV2 was a 2D instrument measuring the horizontal flow components only. All hydrodynamic instruments were sampled at $20 \mathrm{~Hz}$. A right-hand Cartesian coordinate system is adapted throughout. Its origin coincides with the SWL at the location of offshore wave gauge WG1 and its X-axis points onshore along the centerline of the flume section. The z-axis is positive upward. Hence, the cross-shore locations of gauges WG1-WG8 were $\mathrm{x}=0.0,0.25,0.95,8.3,12.9,15.5,17.1$, and $18.6 \mathrm{~m}$.

An impermeable vertical wall with its crest $6 \mathrm{~cm}$ above SWL separated the beach profile from an overwash collection basin. Equipped with a sand trap and a water recirculation system, the collection basin facilitated measurement of water and sediment overwash transport rates at the location of the vertical wall while maintaining a constant SWL in the Sand Tank. The sand trap included a polyester fabric mesh with a micron rating of 74 to retain particles with a diameter exceeding $0.074 \mathrm{~mm}$. Finer 
particles are considered silt and were neglected in the analysis since they only made up $2 \%$. The grain size distributions of the sand collected during each run were determined by sieve analyses to examine possible sorting due to wave overwash.

The bottom morphology in the experiment changed rapidly over the course of a test with the most prominent changes occurring in the region of major profile change encompassing the berm and dune $(16<x<20 m)$. This was mainly due to the intense wave action and high surge level which caused major wave-induced overwash events and destruction of the dune. A laser line scanner system installed on a motorized cart measured longshore transects of the bottom profile in a continuous fashion before and after each run. A fixed laser range finder measured the cross-shore position of the cart during a scan. Transects were scanned using $2 \mathrm{~cm}$ cross-shore intervals to obtain 3D morphology information of the entire bed. The overall accuracy of the laser scans is $\pm 1 \mathrm{~mm}$. For our analysis this 3D data was reduced to $2 \mathrm{D}$ cross-shore profiles by averaging over each transect. Table 1 lists the number of runs, the total duration and the number of profile scans for the $\mathrm{BD}, \mathrm{WD}$, and $\mathrm{SD}$ tests.

\begin{tabular}{|l|c|c|c|}
\hline \multicolumn{4}{|l|}{ Table 1. BD, WD, and SD test overview. } \\
\hline & BD & WD & SD \\
\hline $400-s$ runs & 18 & 12 & 15 \\
total duration & $7200 \mathrm{~s}$ & $4800 \mathrm{~s}$ & $6000 \mathrm{~s}$ \\
profile scans & 19 & 13 & 16 \\
\hline
\end{tabular}

\section{DATA ANALYSIS}

The first $20 s$ of the recorded time series in every run were excluded from the analysis to avoid ramp-up issues. This left approximately 200 waves per run which was sufficient for the statistical analysis explained in the following. The mean value of the free surface elevation $\bar{\eta}$, its standard deviation $\sigma_{\eta}$, and the wet probability $P_{w}$ were extracted from the time series recorded by WG1 - WG8. WG8 was located in the intermittently wet and dry zone of the profile and was buried in the sand above SWL before the initial runs of the BD, WD, and SD tests. Positive (negative) $\bar{\eta}$ values indicate setup (setdown) and $\sigma_{\eta}$ is related to the spectral significant wave height by $H_{m o}=4 \sigma_{\eta}$. A modified procedure for analyzing the data from gauges buried in the sand above SWL was introduced to yield $\bar{\eta}, \sigma_{\eta}$, and the wet probability $P_{w}$ at profile locations in the intermittently wet and dry zone (Figlus et al. 2010). The wet probability $P_{w}$ is calculated as the ratio of wet duration and total run duration. The wet duration is the time a certain point on the bottom profile is submerged under water. The associated wet probability $P_{w}$ indicates the likelihood of that point to be submerged at any given time during a run and can vary between zero for no submergence and unity for complete submergence at all times.

The mean cross-shore velocity component, $\bar{u}$, and its standard deviation, $\sigma_{u}$, are computed from the velocity measurements taken at two different cross-shore locations $2 / 3$ of the local water depth below SWL. This elevation above the local bottom guaranteed for measurements well outside the bottom boundary layer with enough clearance to prevent scouring caused by the probe tip. In addition, the distance from the free surface minimized the negative effects of entrained air bubbles on the measurements. Even though the vertical distribution of the instantaneous velocities is influenced by many factors like orbital wave motion, undertow current and turbulent velocities, the chosen measurement location was assumed to give a fairly good representation of the depth-averaged mean velocities $\bar{U}$. Examples of hydrodynamic data collected during the $\mathrm{BD}$ test are presented together with numerical results in the data comparison section.

The profile evolution associated with the destruction of the dunes by wave-induced overwash was recorded via high-resolution laser scans. As indicated in Table 1, the resilience of the different initial dune profiles against destruction depended on the initial dune geometry. Due to the energy dissipating properties of the berm, the BD test showed the best resistance against the irregular wave attack. A total of 18 runs were required to complete the test and erode the entire beach to a level below SWL, compared to only 12 runs for the WD test and 15 runs for the SD test.

The nineteen measured profiles in the BD test are shown in the left panel of Fig. 2 in the region of major profile change $(16<x<20 m)$. In addition, the measured water overtopping rate $q_{o}$ and the combined onshore bedload and suspended load transport rate $q_{b s}$ over the dune are plotted as functions of time $t$ in the two right panels of Fig. 2. The profile evolution, water overtopping rate and sediment 
overwash rate all indicate a rapid transition between minor and major overwash during which the dune is eroded completely, the water overtopping rate increases to values just below $20 \mathrm{~cm}^{2} / \mathrm{s}$ and the sediment overwash rate jumps to values around $0.5 \mathrm{~cm}^{2} / \mathrm{s}$. Even though this transition occurs at different times for each test, the general process is the same and can be divided into three distinct phases of dune profile evolution and overwash processes to simplify the analysis for the BD, WD, and SD tests. The three phases are delimited by color coded thick lines in all three panels of Fig. 2 for the example of the BD test.
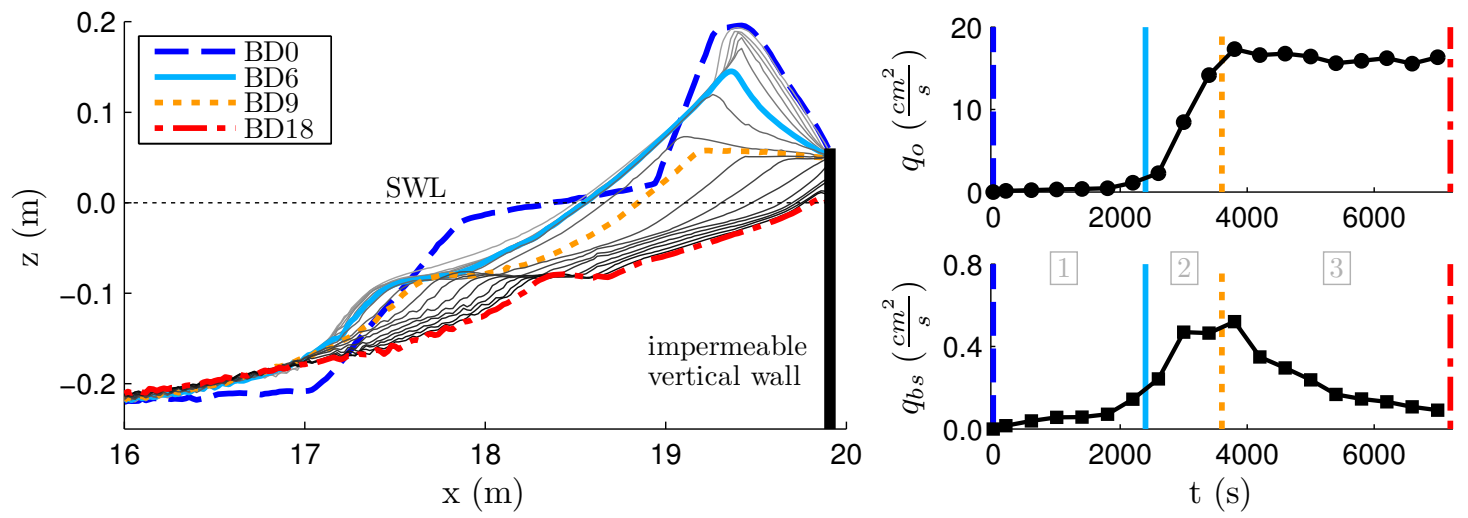

Figure 2. Measured 19 dune profiles in front of the vertical wall for the BD test (left panel). Measured wave overtopping rate $q_{o}$ (top right) and combined bedload and suspended load overwash rate $q_{b s}$ (bottom right) per unit width as a function of time $t$. Three evolution phases are demarcated by thick colored lines.

Phase 1 includes the initial adjustment of the dune profile to the wave and surge conditions where scarping and slumping at the dune face and mostly offshore sediment transport combined with minor wave overtopping $\left(q_{o}<2 \mathrm{~cm}^{2} / \mathrm{s}\right)$ and minor overwash $\left(q_{b s}<0.2 \mathrm{~cm}^{2} / \mathrm{s}\right)$ cause moderate lowering of the dune crest. During Phase $2, q_{b s}$ and $q_{o}$ increase rapidly to their maximum values leading to complete destruction of the dune and the formation of a horizontal plateau in front of the vertical wall. The third phase exhibits the most prominent influence of the vertical wall as erosion of the entire nearshore profile continues and the vertical wall becomes exposed. Fairly constant $q_{o}$ values $\left(q_{o}<15 \mathrm{~cm}^{2} / \mathrm{s}\right)$ are accompanied by decreasing $q_{b s}$ values to around $0.1 \mathrm{~cm}^{2} / \mathrm{s}$ at the end of the test. The exposed wall prohibits onshore bedload transport yielding a gradual reduction in overwash sediment concentration to $0.5 \%$.

Due to the continued wave overtopping and overwash, the beach profiles at the end of each test are not in equilibrium. In this experiment up to $80 \%$ of the sand that eroded from the initial dune profiles moved onshore to be collected as overwash in the sand trap. The sieve analyses of the collected overwash sand revealed that the fraction of larger grains increased as $q_{b s}$ increased but the median diameter of the size distribution remained constant. The numerical model presented in the following uses only median diameter to describe sediment size.

\section{NUMERICAL MODEL CSHORE}

Based on the present experiment, the numerical cross-shore model CSHORE (Kobayashi et al. 2009 ) is extended to include the capability to compute beach profile changes and transport rates when major overwash occurs. CSHORE is a versatile and computation efficient open-source model. It predicts the cross-shore variation of hydrodynamic and sediment transport variables as well as profile changes for an arbitrary initial beach profile. The model is time and depth-averaged and uses a probabilistic, rather than a time-dependent approach. The computed variables include the mean and standard deviation of the free surface elevation $\eta$ and of the depth-averaged cross-shore velocity $U$, the wet probability $P_{w}$, the suspended load $q_{s}$ and bedload $q_{b}$ sediment transport rates, the wave overtopping rate $q_{o}$ over the crest of the wall, and the bottom profile elevation $z_{b}$. Hydrodynamic input is provided at the offshore boundary $(x=0)$ in form of time series of still water level $S$ above $z=0$, peak period $T_{p}$, mean free surface elevation $\bar{\eta}$ (setup/setdown), and root-mean-square wave height $H_{r m s}=H_{m o} / \sqrt{2}$. The still water level was constant and $S=0$ in the present experiment. 
Fig. 3 shows a conceptual definition sketch for CSHORE. It is a combination of two models and covers the entire submerged and subaerial portion of the bottom profile. The wet model starts at the offshore limit of the computation domain and covers the submerged portion of the bottom profile up to its intersection with the mean water level (MWL) at $x_{r}$. The wet and dry model ranges from the intersection of the still water level (SWL) with the bottom profile at $x_{1}$ to the landward limit of the computation domain at $x_{m}$. In the overlap zone of $x_{1}<x<x_{r}$ the results from the two models are averaged to provide a smooth transition.

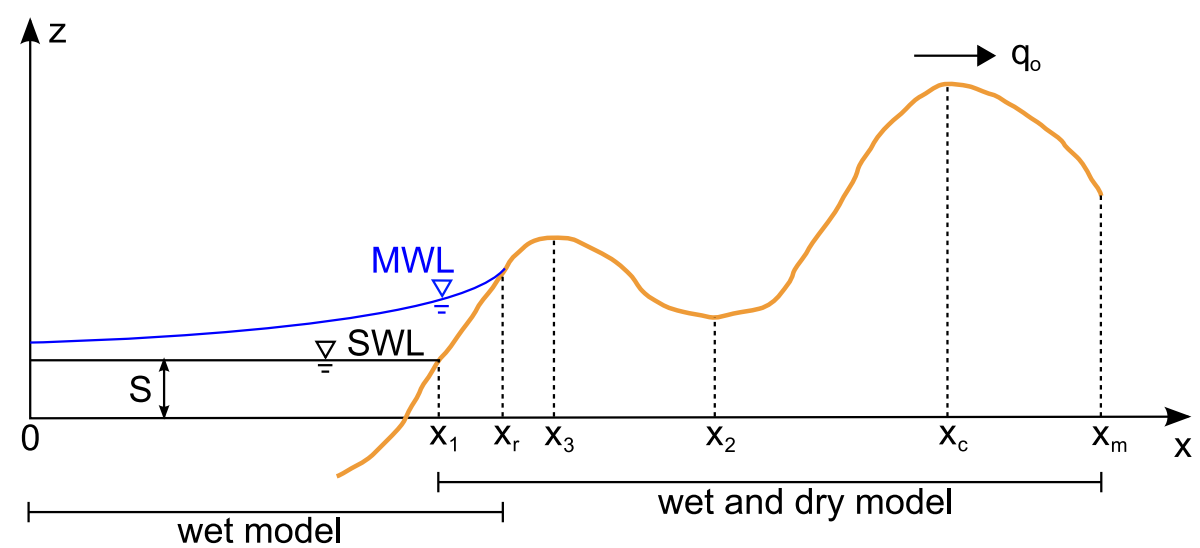

Figure 3. CSHORE definition sketch including the wet model and the wet and dry model.

\section{Wet Model}

The wet model includes wave and current interaction and is based on linear wave theory and the Gaussian distribution of $\eta$ and $U$. Energy dissipation is incorporated via wave breaking and bottom friction. The time-averaged cross-shore numerical model developed by Kobayashi et al. (2009) is extended to include wave and current interactions in order to account for the onshore water flux due to wave overtopping. The time-averaged continuity equation for the impermeable bottom requires that the time averaged volume flux is constant and equal to $q_{o}$. The current velocity felt by waves is given by $q_{o} / \bar{h}$ where $\bar{h}=$ mean water depth given by $\bar{h}=\left(S+\bar{\eta}-z_{b}\right)$ where the overbar denotes time averaging. The effect of the current becomes important in very shallow water where the current $q_{o} / \bar{h}$ may become as large as the phase velocity.

Linear progressive wave theory in finite depth is used to obtain

$$
\sigma_{U}=C \frac{\sigma_{\eta}}{\bar{h}} ; \quad \frac{g \sigma_{\eta}^{2}}{C}+\bar{h} \bar{U}=q_{o}
$$

where $C$ is the phase velocity and $g \sigma_{\eta}^{2} / C$ is the onshore volume flux induced by waves. The relations in Eq. 1 are used to obtain the standard deviation of the depth-averaged cross-shore velocity $\sigma_{U}$ and its mean value $\bar{U}$. The time-averaged return flow velocity $\bar{U}$ is negative (offshore) and the wave overtopping rate $q_{o}$ (onshore) reduces the return flow velocity.

The cross-shore variation of $\bar{\eta}$ is determined from the time-averaged momentum equation

$$
\frac{d}{d x}\left(S_{x x}+\frac{\rho q_{o}^{2}}{\bar{h}}\right)+\rho g \bar{h} \frac{d \bar{\eta}}{d x}+\tau_{b}=0
$$

where $S_{x x}=$ cross-shore radiation stress, $\rho=$ fluid density, and $\tau_{b}=$ time-averaged bottom shear stress. The mean water level $\bar{\eta}$ is induced by the radiation stress $S_{x x}$ and the volume flux $q_{o}$.

In order to predict the cross-shore variation of $\sigma_{\eta}$, in the presence of the volume flux $q_{o}$, the wave action equation is expressed as

$$
\frac{d}{d x}\left(\frac{F_{x}}{\omega}\right)=-\frac{D_{B}+D_{f}}{\omega}
$$


where $F_{x}=$ cross-shore wave energy flux including the effect of $q_{o} ; D_{B}$, and $D_{f}=$ energy dissipation rate per unit horizontal area due to wave breaking, and bottom friction, respectively. The equation of roller energy supplied by $D_{B}$ is used to estimate the roller energy dissipation rate $D_{r}$ which is assumed to cause sediment suspension.

\section{Wet and Dry Model}

The time-averaged cross-shore continuity and momentum equations derived from the nonlinear shallow-water wave equations are expressed as (Kobayashi et al. 1989)

$$
\begin{gathered}
\overline{h U}=q_{o} \\
\frac{d}{d x}\left(\overline{h U^{2}}+\frac{g}{2} \overline{h^{2}}\right)=-g \frac{d z_{b}}{d x} \bar{h}-\frac{1}{2} f_{b} \overline{|U| U}
\end{gathered}
$$

where $h$ and $U=$ instantaneous water depth and cross-shore velocity, respectively. The instantaneous water depth $h$ at given $x$ is described probabilistically rather than in the time domain. Kobayashi et al. (1998) analyzed the probability distributions of the free surface elevations measured in the shoaling, surf and swash zones. The measured probability distributions were shown to be in agreement with the exponential gamma distribution which reduces to the Gaussian distribution offshore and the exponential distribution in the lower swash zone.

The assumption of the exponential distribution is made here to simplify the model in the wet and dry zone. The probability density function $f(h)$ is expressed as

$$
f(h)=\frac{P_{w}^{2}}{\bar{h}} \exp \left(-P_{w} \frac{h}{\bar{h}}\right) \quad \text { for } h>0
$$

with

$$
P_{w}=\int_{0}^{\infty} f(h) d h ; \quad \bar{h}=\int_{0}^{\infty} h f(h) d h
$$

where $P_{w}=$ wet probability for the water depth $\mathrm{h}>0$; and $\bar{h}=$ mean water depth for the wet duration. The dry probability of $h=0$ is equal to $\left(1-P_{w}\right)$. The mean water depth for the entire duration is equal to $P_{w} \bar{h}$. The overbar in Eqs. 4 and 5 indicates averaging for the wet duration only.

The cross-shore velocity $U$ may be related to the depth $h$ in the wet and dry zone and expressed as

$$
U=\alpha \sqrt{g h}+U_{s}
$$

where $\alpha=$ positive constant and $U_{s}=$ steady velocity which is allowed to vary with $x$. The steady velocity $U_{s}$ is included to account for offshore return flow on the seaward slope and the downward velocity increase on the landward slope. Even though a value of $\alpha=2$ was used by Kobayashi et al. (2010) for the prediction of wave overtopping of fixed coastal structures based on bore speed measurements (Holland et al. 1991), a value of $\alpha=1.6$ is adopted for sandy beaches to improve the agreement with measured overtopping and overwash rates for the three laboratory dune overwash tests.

Using Eqs. 6 and 8 the continuity equation yields

$$
q_{o}=\frac{3 \sqrt{\pi} \alpha}{4} \bar{h}\left(\frac{g \bar{h}}{P_{w}}\right)^{1 / 2}+U_{s} \bar{h}
$$

where $P_{w}$ is estimated empirically. The wave overtopping rate $q_{o}$ is the wave-induced onshore volume flux at the crest of a structure or dune and is predicted by imposing $U_{s}=0$ at the crest location $x_{c}$.

\section{Sediment Transport Model}

The presented time-averaged probabilistic model provides the hydrodynamic input required for the following sediment transport model. For the prediction of sediment transport on beaches, the effect of a roller on the steep front of a breaking wave is included in the combined wave and current model because the roller effect increases the offshore return current and improves the agreement of the measured and computed profile evolutions (Kobayashi et al. 2008). The sediment transport rates $q_{b}$ and $q_{s}$ are predicted using the same formulas for the wet zone so that $q_{b}$ and $q_{s}$ are continuous at the SWL shoreline. The continuity equation of bottom sediment is solved numerically to obtain the bottom 
elevation at the next time level. The bottom elevation at the landward end of the computation domain is assumed to be fixed.

Kobayashi et al. (2010) compared CSHORE with 207 tests for wave overtopping and overflow on fixed levees as well as 8 data sets for dune profile evolution with no or minor overwash. The agreement was mostly within a factor 2 . However, the major overwash events in the present experiment are underpredicted by their model. Since numerical computation indicated that the suspended load transport rate $q_{s}$ is an order of magnitude larger than the bedload transport rate $q_{b}$ for this experiment, the formula for $q_{s}$ was modified. In the following, the sediment transport formulas proposed by Kobayashi et al. (2008) for the wet zone are summarized and modified for the wet and dry zone including major overwash.

The probability $P_{b}$ of sediment movement under the Gaussian velocity $U$ in the wet zone is estimated assuming that the sediment movement occurs when the absolute value of the instantaneous bottom shear stress exceeds the critical shear stress corresponding to the critical Shields parameter of 0.05 . The probability $P_{s}$ of sediment suspension is estimated assuming that sediment suspension occurs when the turbulent velocity associated with the instantaneous energy dissipation rate due to bottom friction exceeds the sediment fall velocity. If the estimated $P_{s}$ exceeds $P_{b}$, use is made of $P_{s}=P_{b}$ to ensure that sediment suspension occurs only when sediment movement occurs.

The time-averaged bedload transport rate $q_{b}$ is expressed as

$$
q_{b}=b P_{b} G_{s} \sigma_{U}^{3} /[g(s-1)]
$$

where $b=$ empirical bedload parameter; $G_{s}=$ empirical function of the bottom slope $S_{b}$ and the upper limit 0.63 of the sand slope; and $s=$ sediment specific gravity. The bedload parameter $b$ has been calibrated to be in the range of $0.001-0.004$ using available water tunnel and flume tests on horizontal bottoms for which $G_{s}=1$. The computed profile evolutions and transport rates presented in the following are based on $b=0.002$ (Kobayashi et al. 2009) but are not very sensitive to $b$ because suspended load is computed to be dominant.

The time-averaged cross-shore suspended sediment transport rate $q_{s}$ is expressed as

$$
q_{s}=\left(a \bar{U}+a_{o} U_{o}\right) V_{s}
$$

with

$$
\begin{gathered}
U_{o}=\frac{q_{o}}{\bar{h}} \\
V_{s}=P_{s} V_{B f}\left(1+S_{b}^{2}\right)^{1 / 2} \\
V_{B f}=\frac{e_{B} D_{r}+e_{f} D_{f}}{\rho g(s-1) \omega_{f}}
\end{gathered}
$$

where $a=$ suspended load parameter of the order of 0.2 under the action of waves and wave-induced currents; $a_{o}=$ empirical overwash parameter requiring calibration; $U_{o}=$ onshore current due to the wave overtopping rate $q_{o}$, which is significant only in the zone of very small water depth $\bar{h} ; V_{s}=$ suspended sediment volume per unit horizontal area; $V_{B f}=$ potential suspended sediment volume on a horizontal bottom when $P_{s}=1 ; e_{B}$ and $e_{f}=$ suspension efficiencies for the energy dissipation rates $D_{r}$ and $D_{f}$, previously calibrated as $e_{B}=0.005$ and $e_{f}=0.01$; and $w_{f}=$ sediment fall velocity.

Kobayashi et al. (2009) adjusted the parameter $a=\left(0.2+\sqrt{S_{b} / 0.63}\right)$ for the upward slopes $S_{b}>0$ to increase the offshore suspended sand transport where the return (undertow) current $\bar{U}$ is negative (offshore). Overtopping and overwash rates were measured in the present experiment, leading to the modified suspended sediment transport equation in Eq. 11. The calibrated value of the empirical parameter $a_{0}$ for the present experiment ranges from 2.2 to 3.6 and can be specified in the CSHORE input file. For other cases and field data, $a_{o}$ needs to be adjusted according to the severity of overwash.

The probability $P_{b}$ of sediment movement is obtained for the probability distribution of $U$ based on Eqs. 6 and 8. The movement of sediment particles represented by the median diameter $d_{50}$ is assumed to occur when the instantaneous bottom shear stress given by $0.5 \rho f_{b} U^{2}$ exceeds the critical shear stress $\rho g(s-1) d_{50} \psi_{c}$ with the critical Shields parameter $\psi_{c}=0.05$. The probability $P_{b}$ of sediment movement is then the same as the probability of $|U|>U_{c b}$ with $U_{c b}=\left[2 g(s-1) d_{50} \psi_{c} f_{b}^{-1}\right]^{1 / 2}$ and is given by 


$$
\begin{gathered}
P_{b}=P_{w} \quad \text { for } U_{s}>U_{c b} \\
P_{b}=P_{w} \exp \left[-\frac{P_{w}\left(U_{c b}-U_{s}\right)^{2}}{\alpha^{2} g \bar{h}}\right] \text { for }\left|U_{s}\right| \leq U_{c b} \\
P_{b}=P_{w}\left\{1-\exp \left[-\frac{P_{w}\left(U_{c b}+U_{s}\right)^{2}}{\alpha^{2} g \bar{h}}\right]+\exp \left[-\frac{P_{w}\left(U_{c b}-U_{s}\right)^{2}}{\alpha^{2} g \bar{h}}\right]\right\} \quad \text { for }-U_{s}>U_{c b}
\end{gathered}
$$

where the upper limit of $P_{b}$ is the wet probability $P_{w}$ because no sediment movement occurs during the dry duration. On the other hand, sediment suspension is assumed to occur when the instantaneous turbulent velocity estimated as $\left(f_{b} / 2\right)^{1 / 3}|U|$ exceeds the sediment fall velocity $w_{f}$. The probability $P_{s}$ of sediment suspension is then the same as the probability of $|U|>U_{c s}$ where $U_{c s}=w_{f}\left(2 / f_{b}\right)^{1 / 3}$. The probability $P_{s}$ is given by Eqs. $15-17$ with $U_{c b}$ replaced by $U_{c s}$.

The bedload transport rate $q_{b}$ is estimated using Eq. 10 where the parameter $b$ in the wet and dry zone is chosen so that the values of $q_{b}$ computed for the two different zones are the same at the still water shoreline located at $x=x_{l}$. The suspended sediment transport rate $q_{s}$ is estimated using Eq. 11 where $V_{B f}$ in the wet and dry zone is assumed to be constant and chosen so that the suspended sediment volume $V_{S}$ is continuous at $x=x_{1}$. The assumption of constant $V_{B f}$ may be reasonable because suspended sediment in the wet and dry zone tends to remain suspended in a time-averaged sense. The suspended sediment volume $V_{s}$ per unit horizontal area given in Eq. 13 normally decreases landward because the probability $P_{s}$ of sediment suspension is limited by the wet probability $P_{w}$ which decreases landward.

Finally, the cross-shore sediment transport rates $q_{s}$ and $q_{b}$ computed for the wet zone and the wet and dry zone are averaged in the overlapping zone of $x_{1} \leq x \leq x_{r}$ for the smooth transition between the two zones. The landward limit of the computation is taken as the location of the mean water depth $\bar{h}=d_{50}$ or the landward end of the computation domain. The continuity equation of bottom sediment is solved numerically to obtain the bottom elevation at the next time level (Kobayashi et al. 2009). This computation procedure is repeated starting from the initial bottom profile until the end of each profile evolution computation. The computation time is on the order of $10^{-3}$ of the profile evolution time.

\section{DATA COMPARISON}

\section{Overwash Experiment}

Measured hydrodynamics, profile evolution, wave overtopping and sand overwash rates are compared with CSHORE in the following. The BD test is used as an example here, but the WD and SD test predictions have a similar degree of accuracy. Figlus et al. (2010) compared the same overwash experiment with a previous version of CSHORE. For the computations in this paper the input parameters have been kept the same but the numerical model has been modified. Parameter $\alpha$ in Eq. 8 has been changed from 2 to 1.6 for sandy beaches and a water ponding routine (Figlus et al. 2011) has been added to improve the predictions in the wet and dry zone of the profile. The modifications required recalibration of the overwash parameter $a_{o}$ in Eq. 11 for the present experiment. The new values for the BD, WD, and SD test are 2.2,3.6, and 3.2, respectively.

Fig. 4 displays the measured and computed hydrodynamics for runs BD2 and BD9. Run BD2 (left) is an example of an early stage in Phase 1 and run BD9 (right) shows the results at the end of Phase 2. The region $x<6 \mathrm{~m}$ is omitted since computed and measured values are practically identical and do not vary significantly.

In the top panel the mean water level $\bar{\eta}$ is predicted very well even though measured and computed bottom elevation $z_{b}$ show some discrepancies due to the rapid profile changes in the berm and dune region. Wave height, represented by the free surface standard deviation $\sigma_{\eta}$ decreases landward of WG4 $(x=8.3 \mathrm{~m})$ due to irregular wave breaking. The model slightly underpredicts $\sigma_{\eta}$ at the foot of the berm (WG7 at $x=17.1 \mathrm{~m}$ ) and slightly overpredicts $\sigma_{\eta}$ at the foot of the dune (WG8 at $x$ $=18.6 \mathrm{~m}$ ) in run BD2. In run BD9 only the value at WG7 is slightly underpredicted. The small offshore return current $\bar{U}$ and its standard deviation $\sigma_{U}$ at the ADV1 and ADV2 locations are predicted well in both displayed runs. The magnitude of $\bar{U}$ increases in the backrush dominated region of the foreshore before changing sign to positive onshore wave overtopping flow on the dune. The velocity standard deviation $\sigma_{U}$ increases in very shallow water landward of ADV2 before dropping off again on the dune 
crest. The wet probability $P_{w}$ remains unity in the wet zone seaward of the SWL shoreline and decreases rapidly on the beach face to a small constant value landward of the dune crest. Measured and computed $P_{w}$ values are in good agreement.
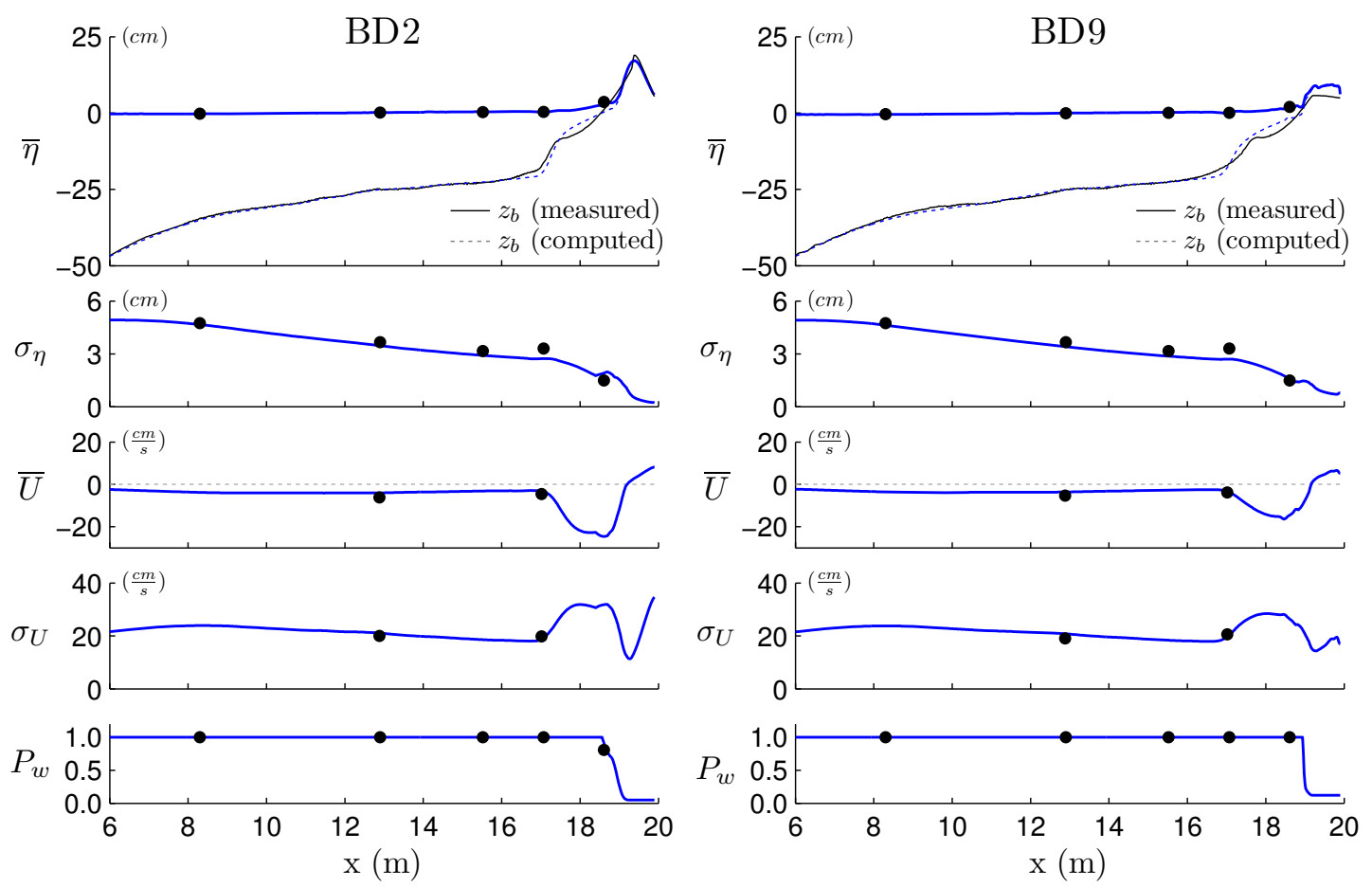

Figure 4. Measured (circles) and computed (solid lines) mean and standard deviation of free surface elevation $\eta$ and depth-averaged velocity $U$ together with wet probability $P_{w}$ for BD2 (left) and BD9 (right).

The measured and computed profile evolution of the BD, WD, and SD tests is shown in Fig. 5 for the end of Phases 1,2, and 3 where the computation was started from the initial profile in each test. Dune crest lowering in Phase 1 and the formation of a plateau in front of the vertical wall at the end of Phase 2 are predicted well with the modified CSHORE model. Beach erosion in front of the exposed vertical wall during Phase 3 is still underpredicted considerably since the numerical model does not consider the wall effects on hydrodynamics and sediment transport explicitly.

Fig. 6 shows the improved prediction of the measured temporal variation of the wave overtopping rate $q_{o}$ (top) and the sediment transport rate $q_{b s}$ (bottom) for the $\mathrm{BD}, \mathrm{WD}$, and SD tests. The transition from minor to major overwash in Phase 2 is demarcated by vertical lines in each panel. The general trend of the temporal variation of $q_{o}$ and $q_{b s}$ is predicted well for all three tests considering the difficulties in accurately predicting the small water depths and large velocities in the wet and dry zone on a moveable bed. The sudden jump in measured overtopping and overwash values appears more gradual in the numerical results. Except for the WD test, $q_{o}$ and $q_{b s}$ are overpredicted before the transition and mostly underpredicted after the transition. 


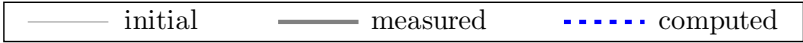

$\mathrm{BD}$
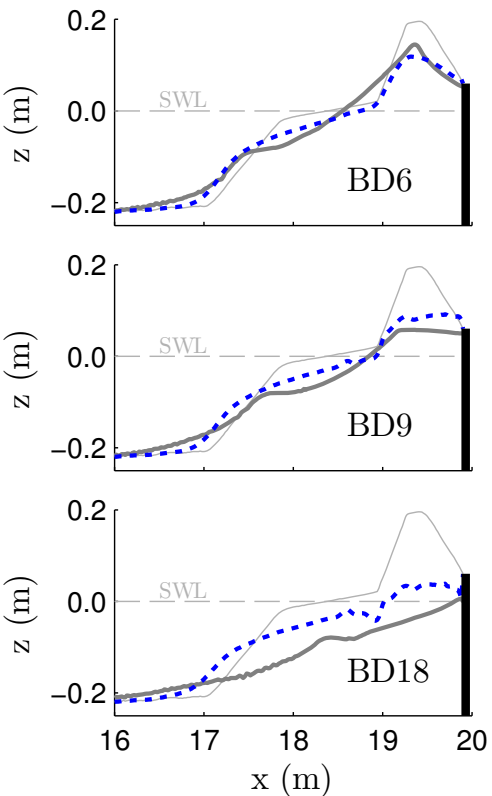

WD
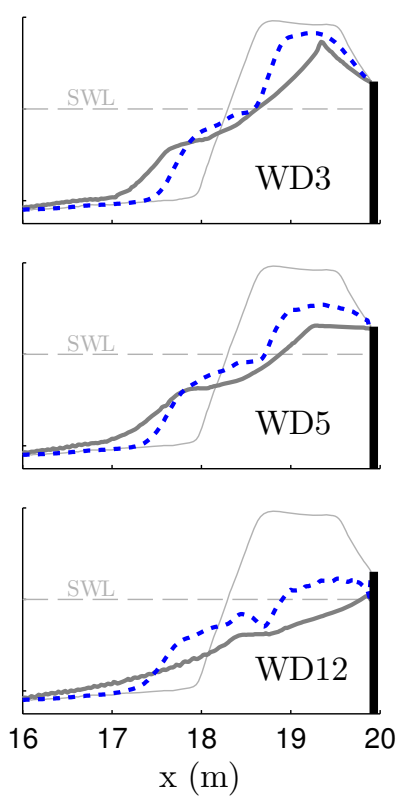

SD

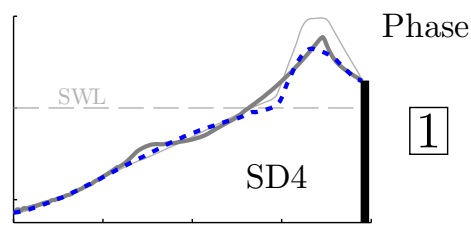

2

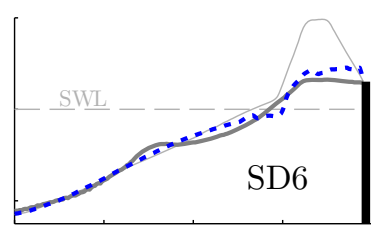

3

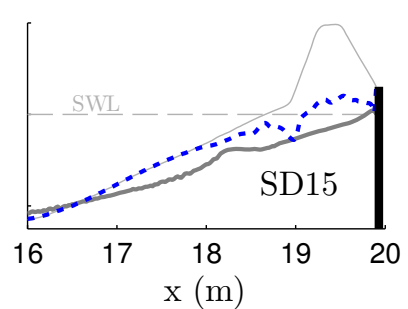

Figure 5. Measured and computed dune profiles at the end of Phases 1, 2, and 3 for BD (left), WD (middle), and SD (right) tests. Initial dune profiles are indicated by thin gray lines.

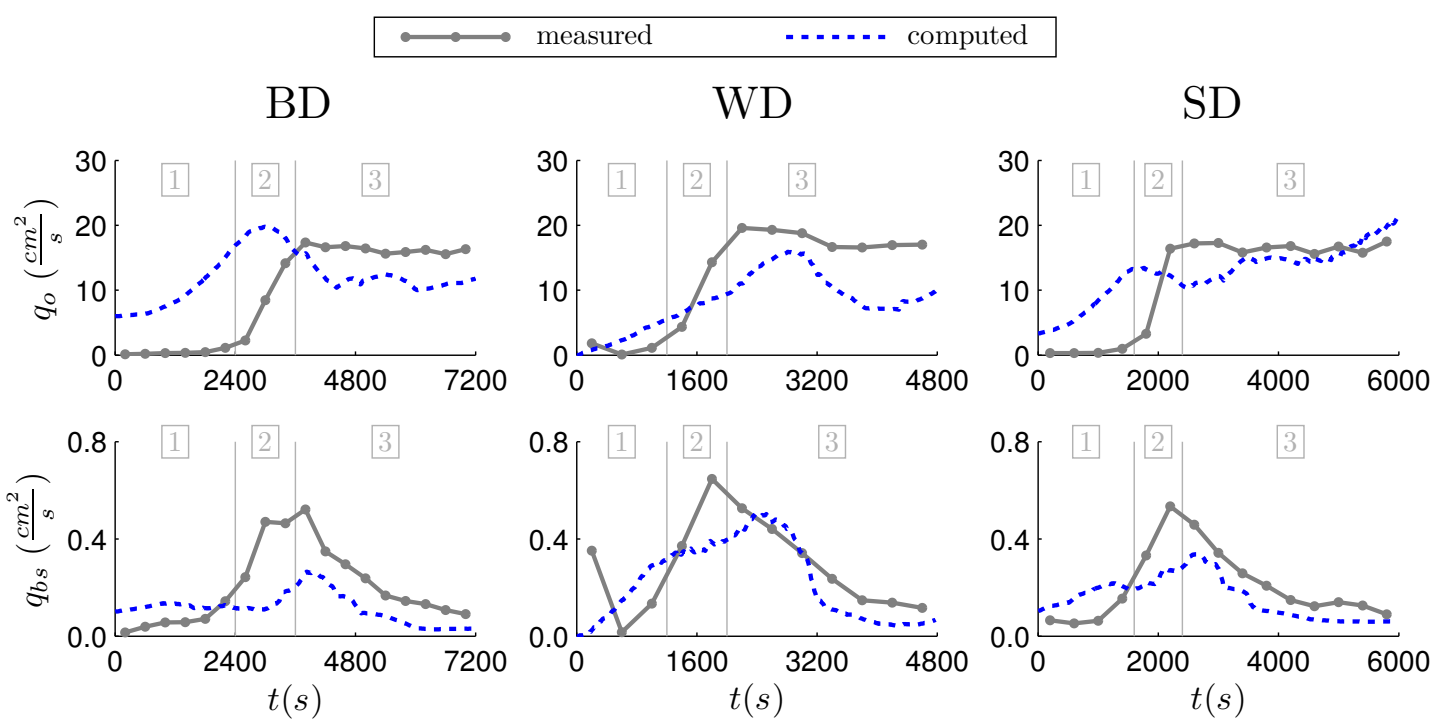

Figure 6. Measured and computed wave overtopping rate $q_{o}$ (top) and sand overwash rate $q_{b s}$ (bottom) for BD (left), WD (middle), and SD (right) tests at the vertical wall. Vertical lines demarcate the three evolution phases. 


\section{Field Dune Data}

Only few field data sets describing overwash of dunes are available. They are limited to pre and post storm profile measurements with considerable time lag between surveys. Flow velocities on the backdune, overtopping rates, and overwash rates during dune overwash have not been measured in the field. In the following, CSHORE is compared with two examples of field data on dune profiles at Dewey Beach, Delaware and Ocean City, Maryland (Wise et al. 1996) to give an idea about the field capabilities of the numerical model. In both cases, the overwash parameter $a_{o}$ (Eq. 11) was calibrated to a value of 0.1 .

The two initial beach profiles shown in Fig. 7 were recorded before being attacked by storms. In the case of Dewey Beach (left panel), substantial dune erosion but no dune lowering occurred during a 4-day storm in December 1992. The storm created a peak significant wave height of $4 m$ and a peak water level of approximately $2 \mathrm{~m}$. Pre and post storm profiles were surveyed on 29 October 1992 and 18 December 1992, respectively. The CSHORE computation was carried out assuming normally incident waves for the duration of 6 days including the storm only. The median grain diameter was $d_{50}$ $=0.33 \mathrm{~mm}$. CSHORE predicts the erosion of the berm and dune face with offshore sediment transport but also shows slight dune crest lowering which was not present in the measurement.
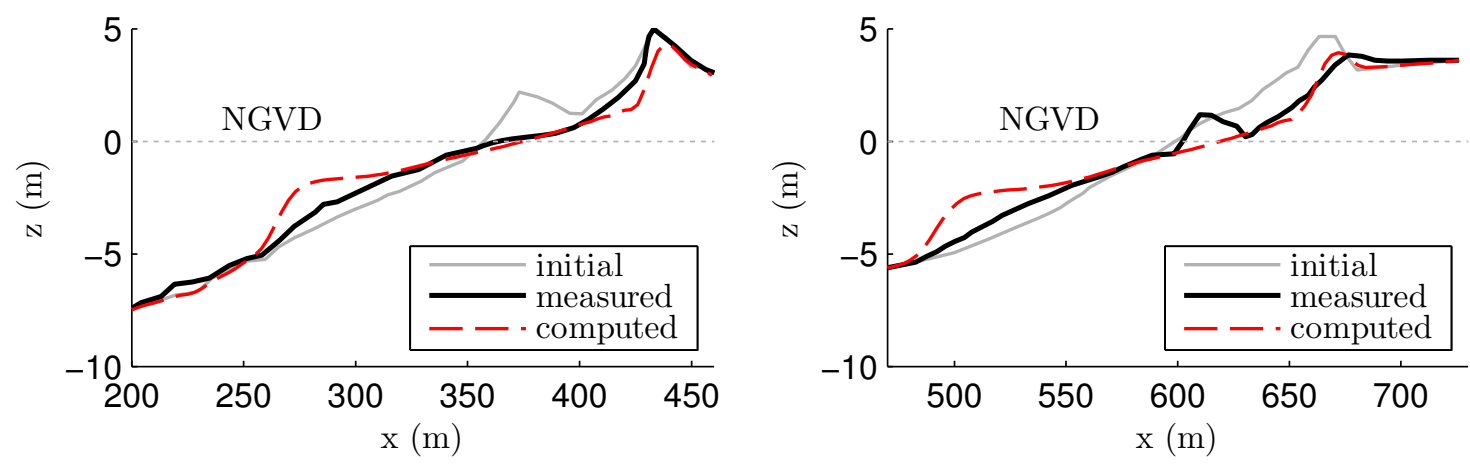

Figure 7. Measured and computed pre and post storm profiles at Dewey Beach, Delaware (left) and Ocean City, Maryland (right). The CSHORE computation only included the storm duration without recovery period.

The measured Ocean City dune profile shows substantial dune crest lowering and landward migration due to overwash and the formation of a berm around the SWL shoreline. The initial profile was surveyed on 26 June 1991 right after a major beach nourishment project. The final measured profile was recorded on 11 January 1992 after being impacted by three storms. The storms occurred on 30 October 1991, 11 November 1991 and 4 January 1992. The October storm lasted about 4 days, with a peak significant wave height of approximately $3 \mathrm{~m}$ and a peak water level of $1.5 \mathrm{~m}$. The November storm lasted about 3 days with a peak significant wave height of $3 \mathrm{~m}$ and a peak water level of $1.2 \mathrm{~m}$. The January storm lasted about 3 days with a peak significant wave height of $4 m$ and a peak water level of $2 \mathrm{~m}$. The numerical computation was carried out for the combined time series of the waves and water level for the three storms, neglecting the intervals between the storms. The median grain diameter was $d_{50}=0.35 \mathrm{~mm}$. CSHORE predicts the dune crest lowering and landward migration well. Deposition landward of the dune is predicted but less than observed in the measured profile. The formation of the berm near the SWL shoreline is not predicted in the model, possibly because the beach recovery after the January storm is not included in the simulation.

The two examples in Fig. 7 underline the sensitivity of profile evolution to overwash events and the difficulty in modeling the occurrence and amount of overwash for given conditions. Recovery periods will have to be included in future computations to improve the numerical results further.

\section{CONCLUSIONS}

The time-averaged probabilistic numerical model CSHORE was modified to improve the predictions of hydrodynamics, profile changes and sediment transport rates in the intermittently wet and dry zone of the beach profile during major dune overwash events. CSHORE combines a model for the wet zone based on linear wave theory with a model for the wet and dry zone based on the nonlinear shallow water wave equations to compute depth-averaged hydrodynamics. The hydrodynamic 
computation is coupled to a sediment transport model to obtain bedload and suspended load transport rates as well as bottom profile changes for arbitrary beach profiles. The sediment transport model has been changed to deal with major overwash events where very shallow water depths and large flow velocities over the dune can cause rapid profile changes. To deal with such situations, an overwash term including the empirical parameter $a_{o}$ was incorporated into the suspended sediment transport formulation.

CSHORE was calibrated using measured profiles, wave overtopping rates and sediment overwash rates during three wave flume tests with different initial dune geometries subject to the same irregular wave conditions at constant water level. The three tests included the following initial profiles made up with the same volume of fine sand in front of a low-crested vertical wall: a berm with a dune (BD), a wide dune (WD) and a slope in front of a dune (SD). Each test was continued until the dune was completely destroyed and the bottom elevation in front of the wall had reached the still water level (SWL). In this experiment related to dune destruction by wave-induced overwash at the peak of a storm, the BD test showed the best resilience requiring a total of 18400 -s runs for completion. The WD and SD tests required 12 and 15 runs, respectively.

The computed cross-shore distribution of the mean free surface elevation, wave height and wet probability compared well with the measurements obtained by eight wave gauges along the flume centerline. The mean and standard deviation of the measured cross-shore velocities using two acoustic Doppler velocimeters was also comparable to the computed depth-averaged values. Detailed beach profiles were measured using a laser line scanner whereas the wave overtopping rate and the onshore sediment transport rate over the dune were measured via a collection basin behind the dune including a sand trap. The measurements revealed a rapid transition from minor to major wave overtopping and sediment overwash during dune destruction. Three phases best explain the observed overtopping, overwash and profile evolution processes. CSHORE is capable of modeling the profile changes during Phases 1 and 2 fairly well which include the initial profile adjustment and offshore sediment transport and the subsequent rapid destruction of the dune. Phase 3 profile erosion in front of the vertical wall is underpredicted and requires further improvement of the numerical model for such cases. The correct prediction of the overtopping and overwash rates is very challenging due to the strong interactions between rapid profile changes, hydrodynamics and sediment transport rates. The modified CSHORE performs fairly well in reproducing the time-dependent wave overtopping and sediment overwash rates measured during the experiment, including the rapid transition during Phase 2.

Field data on wave overtopping of dunes and associated overwash are rare. The comparison of CSHORE with pre and post storm profiles at two sites of dune erosion and dune overwash showed that the good agreement of measured and computed profiles requires $a_{o}$ values one order of magnitude smaller than for the comparison with the overwash experiment. The neglected lateral spreading of overwash flow and overwash sediment on the landward side of the dune may be the reason for the required reduction of the parameter $a_{o}$ to mimic the horizontally two-dimensional effect in this crossshore one-dimensional model. The water ponding routine does not affect these particular computations involving no runnel or dip during the profile evolution. Further improvements of the numerical model may require lateral spreading of overwash in the sediment transport formulation as well as the prediction of beach recovery after a storm to improve and expand its field applications.

\section{ACKNOWLEDGMENTS}

Financial support for the work presented in this paper was granted by the U.S. Army Engineer Research and Development Center under Contract No. W912BU-09-C-0023. We thank the Delaware Department of Natural Resources and Environmental Control (DNREC) and the U.S. Army Corps of Engineers (USACE) for providing pre and post storm profile data.

\section{REFERENCES}

Donnelly, C., N. Kraus, and M. Larson. 2006. State of knowledge on measurement and modeling of coastal overwash, Journal of Coastal Research, 22/4, 965-991, July 2006.

Figlus, J., N. Kobayashi, C. Gralher, and V. Iranzo. 2011. Wave overtopping and overwash of dunes, Journal of Waterway, Port, Coastal, and Ocean Engineering, 137(1), 26-33.

Figlus, J., N. Kobayashi, and C. Gralher. 2011. Onshore migration of emerged ridge and ponded runnel, Journal of Waterway, Port, Coastal, and Ocean Engineering, (submitted).

Holland, K.T., R.A. Holman, and A.H. Sallenger Jr. 1991. Estimation of overwash bore velocities using video techniques, Coastal Sediments '91, ASCE, volume 1, 489-487. 
Kobayashi, N., A. Farhadzadeh, J.A. Melby, B.D. Johnson, and M. Gravens. 2010. Wave overtopping of levees and overwash of dunes, Journal of Coastal Research, 26(5), 888-900.

Kobayashi, N., M. Buck, A. Payo, and B.D. Johnson. 2009. Berm and dune erosion during a storm, Journal of Waterway, Port, Coastal, and Ocean Engineering, 135(1), 1-10.

Kobayashi, N., G.DeSilva, and K. Watson. 1989. Wave transformation and swash on gentle and steep slopes, Journal of Geophysical Research, 94(C1), 951-966.

Kobayashi, N., M. Herrman, B.D. Johnson, and M. Orzech. 1998. Probability distribution of surface elevation in surf and swash zones, Journal of Waterway, Port, Coastal, and Ocean Engineering, 124(3), 99-107.

Kobayashi, N., D.T. Cox, and A. Wurjanto. 1990. Irregular wave reflection and run-up on rough impermeable slopes, Journal of Waterway, Port, Coastal, and Ocean Engineering, 116(6), 708726.

Kobayashi, N., A. Payo, and L. Schmied. 2008. Cross-shore suspended sand and bed load transport on beaches, Journal of Geophysical Research, 113(C07001).

Wise, R.A, S. Smith, and M. Larson. 1996. SBEACH: Numerical model for simulating storm-induced beach change. Report 4. Cross-shore transport under random waves and model validation with SUPERTANK and field data, Technical Report CECR-89-9, U.S. Army Engineer Waterways Experiment Station. 